\title{
Risk of bronchopulmonary dysplasia by second-trimester maternal serum levels of a-fetoprotein, human chorionic gonadotropin, and unconjugated estriol
}

\author{
Laura L. Jelliffe-Pawlowski', Gary M. Shaw², David K. Stevenson², John W. Oehlert ${ }^{2}$, Cele Quaintance ${ }^{2}$, Allan J. Santos ${ }^{2}$, \\ Rebecca J. Baer', Robert J. Currier', Hugh M. O'Brodovich² and Jeffrey B. Gould ${ }^{2}$
}

INTRODUCTION: Although maternal serum a-fetoprotein (AFP), human chorionic gonandotropin (hCG), and estriol play important roles in immunomodulation and immunoregulation during pregnancy, their relationship with the development of bronchopulmonary dysplasia (BPD) in young infants is unknown despite BPD being associated with pre- and postnatal inflammatory factors.

RESULTS: We found that these serum biomarkers were associated with an increased risk of BPD. Risks were especially high when AFP and/or hCG levels were above the 95th percentile and/or when unconjugated estriol (uE3) levels were below the 5th percentile (relative risks (RRs) 3.1-6.7). Risks increased substantially when two or more biomarker risks were present (RRs 9.9-75.9).

DISCUSSION: Data suggested that pregnancies that had a biomarker risk and yielded an offspring with BPD were more likely to have other factors present that suggested early intrauterine fetal adaptation to stress, including maternal hypertension and asymmetric growth restriction.

METHODS: The objective of this population-based study was to examine whether second-trimester levels of AFP, hCG, and uE3 were associated with an increased risk of BPD.

B ronchopulmonary dysplasia (BPD) was originally described in premature infants who had immature lungs and required assisted ventilation with high concentrations of inspired oxygen (1). Many advances in neonatal care, including exogenous surfactant and gentler ventilation, have resulted in the virtual disappearance of old BPD and markedly improved survival of infants who were born after much earlier gestations. Many of these very-low-birth-weight infants also develop a chronic lung disease of infancy, termed "new BPD," which is characterized by an arrest of acinar development $(2,3)$. As reviewed elsewhere $(4,5)$, there are many potential mechanisms, including an inflammatory response within the mother or developing fetus $(5,6)$.

Pro- and anti-inflammatory factors have been found to be associated with an increased risk of new BPD. The epithelial lung fluid in newborns who develop BPD has elevated inflammatory markers and proinflammatory mediators, such as chemokines, adhesion molecules, proinflammatory cytokines, proteases, $(7,8)$ and less anti-inflammatory cytokines $(9,10)$ relative to their preterm peers who do not develop BPD. Similar patterns have been seen in studies measuring proinflammatory cytokines, adhesion molecules, and proteases in amniotic fluid (11), umbilical cord blood (12), and newborn blood $(6,13)$. These data suggest that some newborns may be predisposed to BPD as a result of the effect of systemic inflammation on the developing fetus. For example, recent experimental studies have shown that inflammation during pregnancy combined with neonatal oxidant stress results in a phenotype that is similar to BPD (14).

Given that prenatal inflammation may play a pathophysiological role in the development of BPD, we investigated the relationship between BPD and biomarkers often measured as part of second-trimester screening for chromosomal and neural tube defects that have also been implicated in unusual immunological or inflammatory responses in the pregnant mother and/or developing fetus (15-19). In earlier work, we found that abnormal second-trimester levels of $\alpha$-fetoprotein (AFP), human chorionic gonandotropin (hCG), and unconjugated estriol ( $\mathrm{uE} 3$ ) were associated with an increased risk of preterm birth (20). Given these previous biomarker-preterm findings and the well-studied role of AFP and hCG in immunomodulation and regulation (15-18), and the relationship between estriol and fetal adrenal functioning (19), we considered these markers as prime targets for further investigation of prenatal biomarker-BPD relationships.

\section{RESULTS}

The women included were mostly Hispanic ( $n=373,915 ; 56.4 \%)$, between 18 and 34 years of age $(n=535,002 ; 80.7 \%)$, and multiparous $(n=395,732 ; 59.7 \%)$. About one in 344 pregnancies in the sample resulted in a preterm birth $<30 \mathrm{wk}$ gestational age $(0.3 \%)$, and of those, approximately one in eight $(n=246$, $14.6 \%$ ) had a diagnosis of $\mathrm{BPD}$ (preterm/ $\mathrm{BPD}^{+}$group) based on study criteria. This included $32.8 \%$ of all singleton infants in the sample receiving supplemental oxygen at $36 \mathrm{wk}(n=751)$. 


\section{Articles | Jelliffe-Pawlowski et al.}

Hispanic ethnicity, black race, Pacific Islander race, and nulliparity were found to be significant risk factors for preterm $/ \mathrm{BPD}^{+}$with relative risks (RRs) ranging from 1.4 to 13.7 . This pattern of risk was similar for the preterm infants without a diagnosis of BPD (preterm/BPD- group) (Table 1 ).

Analyses of biomarkers showed that pregnancies with an AFP or hCG multiple of the median (MoM) at or above the 95th percentile were at more than a fourfold increased risk for being diagnosed with BPD (RR 6.7, 95\% confidence interval (CI) 4.8, 9.2; RR $4.1,95 \%$ CI 2.8, 5.8, respectively) as compared with pregnancies with all biomarkers above the 5th and below the 95th percentile. Pregnancies with $\mathrm{uE} 3 \mathrm{MoM}$ at or below the 5th percentile were found to be at more than a threefold increased risk (RR 3.1, 95\% CI 2.0, 4.8). Although the same direction of effect was observed among high AFP and hCG levels and low uE3 levels and preterm/ $\mathrm{BPD}^{-}$and preterm/BPD ${ }^{+}$groups, the magnitude of the RRs tended to be substantially larger in the preterm $/ \mathrm{BPP}^{+}$group, e.g., RR 4.7 and RR 6.5 for AFP, respectively (Table 2).

Analyses by combinations of "at-risk" biomarkers found to be associated with an increased risk of an infant being within the $\mathrm{BPD}^{+}$group (high AFP, high hCG, and/or low uE3) revealed a pattern of substantially increased risk when two or more biomarkers were present for a given pregnancy. For example, a high AFP level in combination with a high hCG level revealed an RR of 14.0 (95\% CI 7.9, 24.8). A high AFP in combination with a low uE3 level (normal hCG) revealed an RR of 9.9 (95\% CI 2.5, 40.2). When all three at-risk patterns were present for a given pregnancy the risk of being within the $\mathrm{BPD}^{+}$group was $>75$ times that of a women with normal AFP, hCG, and uE3 levels ( $\mathrm{RR}=75.9,95 \%$ CI 35.0, 164.6; Table 3).

Within the $\mathrm{BPD}^{+}$group, those with any biomarker risk present (high AFP or hCG and/or low uE3, $n=82$ ) were more likely to have a maternal diagnosis or complication present during pregnancy (64.6\% vs. 51.2\%; Table 4$)$. This was especially true for hypertension and preeclampsia.

As compared with preterm babies in the $\mathrm{BPD}^{+}$group who did not have a biomarker risk present, preterm babies in the $\mathrm{BPD}^{+}$ group whose mothers had an identified biomarker risk tended to be "older" (mean d gestation 190.9 vs. $186.8, P<0.01$ ), of lower weight (mean birth weight $838.0 \mathrm{~g}$ vs. $902.1 \mathrm{~g}, P<0.05$ ), and asymmetrically undergrown (as indicated by significantly lower weights in the biomarker group but not significantly smaller head sizes and greater mean head circumference/birth weight ratios in the biomarker group (cephalization index 0.030 vs. $0.028, P<0.05$; ref. 20). They were also more likely to be small for gestational age (SGA) at birth ( $28.8 \%$ vs. $4.3 \%, P<0.01)$ and were less likely to be diagnosed as having an intraventricular hemorrhage ( $20.7 \%$ vs. $44.5 \%, P<0.01$; Table 5 ).

Exclusion of hypertension from logistic models did not substantially alter biomarker-BPD ${ }^{+}$group findings. After excluding pregnancies with a history of hypertension and adjusting for black or Pacific Islander race/ethnicity, nulliparity, and SGA birth, pregnancies with high AFP levels were at more than a threefold increased risk for being within the $\mathrm{BPD}^{+}$group (RR 3.6, 95\% CI 2.3, 5.7), pregnancies with high hCG levels were at more than a twofold increased risk for being in the $\mathrm{BPD}^{+}$
Table 1. Relative risk of preterm birth occurring with and without BPD by target maternal characteristics and within characteristic risk groupings

\begin{tabular}{|c|c|c|}
\hline & \multicolumn{2}{|c|}{ Preterm birth $<30 \mathrm{wk}$} \\
\hline & $\mathrm{BPD}^{-\mathrm{a}}$ & $\mathrm{BPD}^{+\mathrm{b}}$ \\
\hline & $\begin{array}{c}n(\%) ; \\
\text { RR (95\% Cl) }\end{array}$ & $\begin{array}{c}n(\%) ; \\
\operatorname{RR}(95 \% \mathrm{Cl})\end{array}$ \\
\hline Sample $(n=662,889)$ & $1,682(0.3)$ & $246(0.04)$ \\
\hline \multicolumn{3}{|l|}{ Race/ethnicity } \\
\hline \multirow[t]{2}{*}{ White $(n=187,852)$} & $332(0.2)$ & $53(0.03)$ \\
\hline & Reference & Reference \\
\hline \multirow[t]{2}{*}{ Hispanic $(n=373,915)$} & $1,036(0.3)$ & $145(0.04)$ \\
\hline & $1.6(1.4,1.8)$ & $1.4(1.0,1.9)$ \\
\hline \multirow[t]{2}{*}{ Black $(n=31,901)$} & $204(0.6)$ & $25(0.1)$ \\
\hline & $3.6(3.1,4.3)$ & $2.8(1.7,4.5)$ \\
\hline \multirow[t]{2}{*}{ Asian $(n=48,344)$} & $64(0.1)$ & $17(0.04)$ \\
\hline & $0.7(0.6,1.0)$ & $1.2(0.7,2.2)$ \\
\hline \multirow[t]{2}{*}{ Asian East Indian $(n=14,169)$} & $35(0.3)$ & $1(0.01)$ \\
\hline & $1.4(1.0,2.0)$ & $0.3(0.0,1.8)$ \\
\hline \multirow[t]{2}{*}{ Middle Eastern $(n=4,725)$} & $8(0.2)$ & $1(0.02)$ \\
\hline & $0.9(0.5,1.9)$ & $0.8(0.1,5.4)$ \\
\hline \multirow[t]{2}{*}{ Pacific Islander $(n=1,034)$} & $3(0.3)$ & $4(0.4)$ \\
\hline & $1.6(0.5,5.1)$ & $13.7(5.0,37.8)$ \\
\hline \multicolumn{3}{|l|}{ Maternal age at term (years) } \\
\hline \multirow[t]{2}{*}{$<18(n=9,960)$} & $33(0.3)$ & $3(0.03)$ \\
\hline & $1.4(1.0,1.9)$ & $0.8(0.3,2.6)$ \\
\hline \multirow[t]{2}{*}{$18-34(n=535,002)$} & $1,284(0.2)$ & $192(0.04)$ \\
\hline & Reference & Reference \\
\hline \multirow[t]{2}{*}{$>34(n=117,927)$} & $365(0.3)$ & $51(0.04)$ \\
\hline & $1.3(1.2,1.5)$ & $1.2(0.9,1.6)$ \\
\hline \multicolumn{3}{|l|}{ Maternal weight (percentile)c } \\
\hline \multirow[t]{2}{*}{$<5 \operatorname{th}(n=30,207)$} & $71(0.2)$ & $13(0.04)$ \\
\hline & $0.9(0.7,1.2)$ & $1.2(0.7,2.1)$ \\
\hline \multirow[t]{2}{*}{ 5-95th $(n=601,058)$} & $1,508(0.3)$ & $216(0.04)$ \\
\hline & Reference & Reference \\
\hline \multirow[t]{2}{*}{$>95$ th $(n=31,624)$} & $103(0.3)$ & $17(0.05)$ \\
\hline & $1.3(1.1,1.6)$ & $1.5(0.9,2.5)$ \\
\hline \multicolumn{3}{|l|}{ Parity } \\
\hline \multirow[t]{2}{*}{$1(n=266,774)$} & $828(0.3)$ & $130(0.05)$ \\
\hline & $1.4(1.3,1.6)$ & $1.7(1.3,2.1)$ \\
\hline \multirow[t]{2}{*}{$\geq 2(n=395,732)$} & $854(0.2)$ & $116(0.03)$ \\
\hline & Reference & Reference \\
\hline
\end{tabular}

Unknown $(n=383)$

Relative risks are presented for preterm birth occurring with and without BPD for non-white race/ethnicity groups compared with white race/ethnicity, maternal age $<18$ years or $>34$ years compared with $18-34$ years, maternal weight $<5$ th or $>95$ th weight percentile compared with the 5 th and 95 th percentile, and for parity $=1$ or "unknown" compared with parity $\geq 2$.

BPD, bronchopulmonary dysplasia; $\mathrm{Cl}$, confidence interval; NEC, necrotizing enterocolitis; $\mathrm{RR}$, relative risk.

aDue to an increased likelihood that this subgroup might include infants with BPD based on a less restrictive definition, preterm infants $(<30 \mathrm{wk})$ were excluded if they were on oxygen at $28 \mathrm{~d}$ and/or at $36 \mathrm{wk}$. ${ }^{\mathrm{b}} \mathrm{BPD}$ was defined as gestational age between $25 w k+0 d$ and $29 w k+6 \mathrm{~d}$ (inclusive); birth weight <1,500 g; no birth defects/ congenital anomalies; no surgeries except circumcision or patent ductus arteriosus ligation; having NEC is not an exclusion but NEC surgery is an exclusion; in the hospital and on continuous oxygen at $36 \mathrm{wk}$; on ventilator for $\geq 3 \mathrm{~d}$. "Weight percentile by race/ ethnicity grouping at weeks of gestation at initial testing. 
Table 2. Log binomial regression analyses: preterm birth $<30 \mathrm{wk}$ occurring with and without BPD by overall biomarker groupings

\begin{tabular}{|c|c|c|}
\hline & \multicolumn{2}{|c|}{ Preterm birth $<30$ wk } \\
\hline & $\mathrm{BPD}^{-\mathrm{a}}$ & $\mathrm{BPD}^{+\mathrm{b}}$ \\
\hline & $\begin{array}{c}n(\%) \\
\operatorname{RR}^{\operatorname{Adj}}(95 \% \mathrm{Cl})^{c}\end{array}$ & $\begin{array}{c}n(\%) \\
\operatorname{RR}^{\operatorname{Adj}}(95 \% \mathrm{Cl})^{\mathrm{d}}\end{array}$ \\
\hline Sample $(n=662,890)$ & $1,682(0.3)$ & $246(0.04)$ \\
\hline \multirow{2}{*}{$\begin{array}{l}\text { No abnormal biomarkers } \\
(n=513,480)\end{array}$} & $1,066(0.2)$ & $140(0.03)$ \\
\hline & Reference & Reference \\
\hline \multicolumn{3}{|c|}{ Any “high" biomarker (MoM $\geq 95$ th percentile) } \\
\hline \multirow[t]{2}{*}{$\operatorname{AFP}(n=27,680)$} & $267(1.0)$ & $52(0.2)$ \\
\hline & $4.5(3.9,5.1)$ & $6.7(4.8,9.2)$ \\
\hline \multirow[t]{2}{*}{$\operatorname{hCG}(n=31,519)$} & $190(0.6)$ & $38(0.1)$ \\
\hline & $2.8(2.4,3.3)$ & $4.1(2.8,5.8)$ \\
\hline \multirow[t]{2}{*}{ uE3 $(n=22,649)$} & $98(0.4)$ & $11(0.05)$ \\
\hline & $2.0(1.6,2.5)$ & $1.7(0.9,3.1)$ \\
\hline \multicolumn{3}{|c|}{ Any"low" biomarker (MoM $\leq 5$ th percentile) } \\
\hline \multirow[t]{2}{*}{$\operatorname{AFP}(n=28,596)$} & $33(0.1)$ & $10(0.03)$ \\
\hline & $0.6(0.4,0.8)$ & $1.3(0.7,2.5)$ \\
\hline \multirow[t]{2}{*}{ hCG $(n=31,481)$} & $86(0.3)$ & $10(0.03)$ \\
\hline & $1.3(1.1,1.6)$ & $1.2(0.6,2.3)$ \\
\hline \multirow[t]{2}{*}{$\mathrm{uE} 3(n=27,255)$} & $122(0.5)$ & $23(0.1)$ \\
\hline & $2.2(1.8,2.6)$ & $3.1(2.0,4.8)$ \\
\hline
\end{tabular}

AFP, a-fetoprotein; BPD, bronchopulmonary dysplasia; $\mathrm{Cl}$, confidence interval; hCG, human chorionic gonadotropin; MoM, multiple of the median; NEC, necrotizing enterocolitis; $R^{A d j}$, adjusted relative risk; SGA, small for gestational age; uE3, unconjugated estriol.

aDue to an increased likelihood that this subgroup might include infants with BPD based on a less restrictive definition, preterm infants $(<30 \mathrm{wk})$ were excluded if they were on oxygen at $28 \mathrm{~d}$ and/or at $36 \mathrm{wk}$. ${ }^{\circ} \mathrm{BPD}$ was defined as gestational age between $25 w k+0 d$ and $29 w k+6 d$ (inclusive); birth weight $<1,500$ g; no birth defects/ congenital anomalies; no surgeries except circumcision or patent ductus arteriosus ligation; having NEC is not an exclusion but NEC surgery is an exclusion; in the hospital and on continuous oxygen at $36 \mathrm{wk}$; on ventilator for $\geq 3 \mathrm{~d}$. 'Binomial analyses included all maternal characteristics found to be predictive of preterm birth $<30 \mathrm{wk}$ without BPD (maternal age $>34$ years and race/ethnicity $=$ Hispanic or black (yes vs. no), parity $=1$ (yes vs. no), and SGA birth (yes vs. no). ${ }^{\mathrm{d} B i n o m i a l}$ analyses included all maternal characteristics found to be predictive of BPD (race/ethnicity = black or Pacific Islander (yes vs. no) and parity $=1$ (yes vs. no)) and SGA birth (yes vs. no). ${ }^{\text {AFP, }, ~ h C G, ~}$ and $\mathrm{uE} 3 \mathrm{MoMs}$ all between the 5 th and 95 th percentiles (AFP $>0.58,<1.80$; $\mathrm{hCG}>0.41$, $<2.38$; uE3 $>0.59,<1.57)$.

group (RR 2.3, 95\% CI 1.4, 3.8), and pregnancies with a low $\mathrm{uE3}$ level were at a twofold increased risk for being within the $\mathrm{BPD}^{+}$group (RR 2.1, 95\% CI 1.2, 3.8; data not shown).

\section{DISCUSSION}

We found that one in three pregnancies resulting in a baby within the $\mathrm{BPD}^{+}$group had an "at-risk" second-trimester maternal serum biomarker pattern independent of preterm delivery. Compared with pregnancies in the $\mathrm{BPD}^{+}$group for whom there were no biomarker risks present, $\mathrm{BPD}^{+}$infants who had mothers with a second-trimester biomarker risk present were more likely to be SGA and have mothers with maternal complications such as hypertension and preeclampsia. Such findings may prove useful to future research efforts
Table 3. Log binomial regression analyses: preterm birth $<30 \mathrm{wk}$ occurring with and without BPD by specific biomarker patterns

\begin{tabular}{|c|c|c|}
\hline & $\mathrm{BPD}^{-\mathrm{a}}$ & $\mathrm{BPD}^{+\mathrm{a}}$ \\
\hline & $\begin{array}{c}n(\%) ; \\
\operatorname{RR}^{\operatorname{Adj}}(95 \% \mathrm{Cl})^{\mathrm{b}}\end{array}$ & $\begin{array}{c}n(\%) \\
\operatorname{RR}^{\text {Adj }}(95 \% \mathrm{Cl})^{\mathrm{b}}\end{array}$ \\
\hline Sample $(n=662,890)$ & $1,682(0.3)$ & $246(0.04)$ \\
\hline \multirow{2}{*}{$\begin{array}{l}\text { No abnormal biomarkers } \\
(n=513,480)\end{array}$} & $1,066(0.2)$ & $140(0.03)$ \\
\hline & Reference & Reference \\
\hline \multicolumn{3}{|l|}{ Specific biomarker pattern ${ }^{d}$} \\
\hline \multirow[t]{2}{*}{ Isolated high AFP $(n=22,936)$} & $181(0.8)$ & $30(0.1)$ \\
\hline & $3.8(3.3,4.5)$ & $4.9(3.3,7.2)$ \\
\hline \multirow[t]{2}{*}{ Isolated high hCG $(n=25,447)$} & $95(0.4)$ & $16(0.1)$ \\
\hline & $1.8(1.5,2.2)$ & $2.3(1.4,3.9)$ \\
\hline \multirow[t]{2}{*}{ Isolated low uE3 $(n=23,870)$} & $74(0.3)$ & $12(0.1)$ \\
\hline & $1.5(1.2,1.9)$ & $1.9(1.1,3.4)$ \\
\hline \multirow[t]{2}{*}{ High AFP, high hCG $(n=3,514)$} & $59(1.7)$ & $13(0.4)$ \\
\hline & $8.3(6.4,10.8)$ & $14.0(7.9,24.8)$ \\
\hline \multirow[t]{2}{*}{ High AFP, low uE3 ( $n=837)$} & $12(1.4)$ & $2(0.2)$ \\
\hline & $7.4(4.2,13.0)$ & $9.9(2.5,40.2)$ \\
\hline \multirow[t]{2}{*}{ High hCG, low uE3 $(n=2,165)$} & $21(1.0)$ & $2(0.1)$ \\
\hline & $6.4(3.1,7.4)$ & $3.6(0.9,14.6)$ \\
\hline $\begin{array}{l}\text { High AFP, high hCG, low uE3 } \\
(n=393)\end{array}$ & $15(3.8)$ & $7(1.8)$ \\
\hline
\end{tabular}

$20.9(12.6,34.6) \quad 75.9(35.0,164.6)$

AFP, a-fetoprotein; BPD, bronchopulmonary dysplasia; Cl, confidence interval; hCG, human chorionic gonadotropin; MoM, multiple of the median; NEC, necrotizing enterocolitis; $\mathrm{RR}^{\mathrm{Adj}}$, adjusted relative risk; $\mathrm{uE3}$, unconjugated estriol.

aPPD was defined as gestational age between $25 \mathrm{wk}+0 \mathrm{~d}$ and $29 \mathrm{wk}+6 \mathrm{~d}$ (inclusive); birth weight <1,500 g; no birth defects/congenital anomalies; no surgeries except circumcision or patent ductus arteriosus ligation; having NEC is not an exclusion but NEC surgery is an exclusion; in the hospital and on continuous oxygen at $36 \mathrm{wk}$; on ventilator for $\geq 3 \mathrm{~d}$. ${ }^{b}$ Given power considerations only small-for-gestational-age birth was considered in adjusted models. 'AFP, hCG, and UE3 MoMs all between the 5 th and 95th percentiles (AFP $>0.58,<1.80 ; \mathrm{hCG}>0.41,<2.38$; UE3 $>0.59,<1.57$ ). ${ }^{\mathrm{d} C o m p u t e d ~ f o r ~}$ all low and/or high biomarkers found to be associated with an increased risk for BPD in initial analyses.

in this area given that they may provide clues to underlying pathophysiological processes that might signal BPD.

Although a number of studies have examined the relationship between second-trimester maternal serum levels of AFP, hCG, and uE3 and preterm birth $(21,22,23)$, to the best of our knowledge, this study is the first to examine these relationships among a subset of preterm births with BPD. The observed findings with respect to an increased risk of preterm birth among pregnancies with high AFP, high hCG, and/or low uE3 were similar in direction to several other studies of biomarkers and preterm birth $(21,22)$. However, our finding that the magnitude of association between these biomarker patterns and preterm birth occurring with BPD was particularly increased as compared with that for preterm birth without BPD suggests a particularly salient biomarker-BPD link. That no differences in risk for BPD were noted for the high $\mathrm{uE3}$ group or the low hCG group but such differences were found for the preterm $\mathrm{BPD}^{-}$group provides further evidence that the biomarker 


\section{Articles | Jelliffe-Pawlowski et al.}

Table 4. Maternal diagnoses and complications: pregnancies resulting in an infant with BPD based on study criteria with and without a biomarker risk

\begin{tabular}{|c|c|c|}
\hline & \multicolumn{2}{|c|}{ BPD with biomarker risk ${ }^{\mathrm{a}}$} \\
\hline & $\begin{array}{l}\text { No; } \\
n(\%)\end{array}$ & $\begin{array}{l}\text { Yes; } \\
n(\%)\end{array}$ \\
\hline Any maternal diagnosis or complication $(n=513,480)$ & $84(51.2)$ & $53(64.6)^{*}$ \\
\hline Any hypertension, preeclampsia, eclampsia & $28(17.1)$ & $40(48.8)^{* *}$ \\
\hline Eclampsia & $1(0.6)$ & - \\
\hline \multicolumn{3}{|l|}{ Other specific pregnancy complications } \\
\hline Bleeding/abruption/previa & $28(17.1)$ & $13(15.9)$ \\
\hline Cervical incompetence & $12(7.3)$ & $1(1.2)^{*}$ \\
\hline Trauma & $1(0.6)$ & - \\
\hline \multicolumn{3}{|l|}{ Other diagnosed disorders/conditions } \\
\hline \multirow[t]{2}{*}{ Neoplasms } & $3(1.8)$ & $1(1.2)$ \\
\hline & $\begin{array}{l}\text { (Liver (1), leiomyoma of uterus (1), } \\
\text { neurofibromatosis (1)) }\end{array}$ & (Leiomyoma of uterus (1)) \\
\hline \multirow[t]{2}{*}{ Blood and blood-forming organs } & $2(1.2)$ & $3(3.7)$ \\
\hline & (Thalassemia (1), anemia (1)) & $\begin{array}{l}\text { (Sickle-cell disease (1), anemia (1), } \\
\text { thrombocytopenia (1)) }\end{array}$ \\
\hline Endocrine, metabolic & $4(2.4)$ & - \\
\hline \multirow[t]{2}{*}{ Respiratory system } & $3(1.8)$ & $3(3.7)$ \\
\hline & $\begin{array}{l}\text { (Asthma (1), pulmonary edema (1), } \\
\text { pulmonary insufficiency (1)) }\end{array}$ & (Asthma (2), pulmonary edema (1)) \\
\hline \multirow[t]{2}{*}{ Digestive system } & $1(0.6)$ & - \\
\hline & (Appendicitis (1)) & \\
\hline \multirow[t]{2}{*}{ Genitourinary } & $3(1.8)$ & $1(1.2)$ \\
\hline & (Old laceration of cervix (3)) & $\begin{array}{l}\text { (Unspecified disorder of kidneys and ureter } \\
\text { (1)) }\end{array}$ \\
\hline \multirow[t]{2}{*}{ Skin } & - & $1(1.2)$ \\
\hline & & (Lupus erythematosus) \\
\hline Any maternal infection & $15(9.2)$ & $3(3.7)$ \\
\hline Any uterine infection $^{\mathrm{b}}$ & $14(8.5)$ & $2(2.4)$ \\
\hline \multirow[t]{2}{*}{ Any viral infection } & $1(0.6)$ & $1(1.2)$ \\
\hline & $(\mathrm{CMV}(1))$ & $(\mathrm{CMV}(1), \operatorname{HIV}(1)$ (same pregnancy)) \\
\hline \multicolumn{3}{|l|}{ Other } \\
\hline Indomethacin administration & $106(64.6)$ & $51(62.2)$ \\
\hline
\end{tabular}

AFP, a-fetoprotein; BPD, bronchopulmonary dysplasia; CMV, cytomegalovirus; $\mathrm{hCG}$, human chorionic gonadotropin; MoM, multiple of the median; uE3, unconjugated estriol.

${ }^{a}$ AFP MoM $\geq 95$ th percentile $(M O M \geq 1.80)$, hCG MoM $\geq 95$ th percentile $(M O M \geq 2.38)$, or $\mathrm{UE3} \mathrm{MOM} \leq 5$ th percentile $(\mathrm{MoM} \leq 0.59)$. ${ }^{\circ}$ nncludes amnionitis, chorioamnionitis, and endometritis (specific diagnoses not coded for full sample in source database(s)). ${ }^{*} P<0.05 ;{ }^{* *} P<0.01$. 
Table 5. Infant characteristics and specific outcomes: pregnancies with and without a biomarker risk resulting in an infant with BPD based on study criteria

\begin{tabular}{|c|c|c|}
\hline & \multicolumn{2}{|c|}{ BPD with biomarker risk ${ }^{a}$} \\
\hline & No $(n=164)$ & Yes $(n=82)$ \\
\hline & Mean (SD), range & Mean (SD), range \\
\hline \multirow[t]{2}{*}{ Days gestation } & $186.8(9.7)$ & $190.9(10.7)^{* *}$ \\
\hline & $166-211$ & $170-223$ \\
\hline \multirow[t]{2}{*}{ Birth weight (g) } & $902.1(186.8)$ & $838.0(213.3)^{*}$ \\
\hline & $509-1440$ & $422-1375$ \\
\hline \multirow[t]{2}{*}{ Head circumference $(\mathrm{cm})^{\mathrm{b}}$} & $24.3(1.7)$ & $24.5(2.5)$ \\
\hline & $21-29$ & $19-34$ \\
\hline \multirow{2}{*}{$\begin{array}{l}\text { Head circumference/birth } \\
\text { weight ratio }{ }^{b}\end{array}$} & $0.028(0.004)$ & $0.030(0.007)^{*}$ \\
\hline & $0.019-0.039$ & $0.020-0.054$ \\
\hline \multirow[t]{3}{*}{ Total days on ventilator } & $26.3(18.5)$ & $30(22.4)$ \\
\hline & $3-91$ & $3-110$ \\
\hline & $n(\%)$ & $n(\%)$ \\
\hline$S G A^{c}$ & $7(4.3)$ & $22(26.8)^{* *}$ \\
\hline Apgar at $1 \mathrm{~min} \leq 3$ & $30(18.3)$ & $21(25.6)$ \\
\hline Apgar at $5 \min \leq 3$ & $9(5.5)$ & $2(2.4)$ \\
\hline Baby death in NICU & $2(1.2)$ & $3(3.7)$ \\
\hline Any infant infection & $42(25.6)$ & $27(32.9)$ \\
\hline Group B streptococcus & $9(5.5)$ & $5(6.1)$ \\
\hline Early bacterial sepsis & $6(3.7)$ & $1(1.2)$ \\
\hline Late bacterial sepsis & $30(18.3)$ & $22(26.8)$ \\
\hline Late fungal sepsis & - & $1(1.2)$ \\
\hline Retinopathy of prematurity & $98(59.8)$ & $54(65.9)$ \\
\hline Patent ductus arteriosus & $138(84.2)$ & $63(76.8)$ \\
\hline Intraventricular hemorrhage & $73(44.5)$ & $17(20.7)^{* *}$ \\
\hline \multicolumn{3}{|c|}{$\begin{array}{l}\text { AFP, a-fetoprotein; BPD, bronchopulmonary dysplasia; CPQCC, California Perinatal } \\
\text { Quality Care Collaborative; } \mathrm{hCG} \text {, human chorionic gonadotropin; MoM, multiple } \\
\text { of the median; NICU, neonatal intensive care unit; SGA, small for gestational age; } \\
\text { uE3, unconjugated estriol. }\end{array}$} \\
\hline \multicolumn{3}{|c|}{ 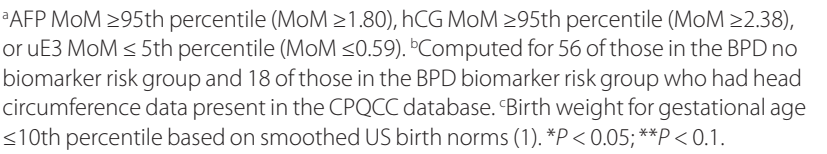 } \\
\hline
\end{tabular}

patterns observed may imply important pathophysiological processes relevant to the development of BPD. Given the known associations between BPD and inflammation $(6,12,13)$ and the demonstrated relationship between studied biomarkers and immunological and inflammatory related processes (16-19), it is plausible that the observed relationships between these biomarkers and BPD relate directly and/or indirectly to immune system function and inflammation.

Mid-pregnancy serum AFP and hCG levels are thought to be closely related to an immunosuppressive response of the mother that aims to prevent the rejection of fetoplacental tissues $(24,25)$. Given that AFP is produced by the yolk sac and fetal liver (26) and hCG is produced primarily by placental cells (27), the particularly high risk of BPD observed in pregnancies with high levels of one or both of these biomarkers in the second trimester may point to an especially elevated attempt at an immunosuppression response by the mother and/or developing fetus. Evidence of this tie among observed biomarker levels, a particularly heightened immunosuppressive response, and BPD may also be indicated by the increased risk of BPD among pregnancies with especially low levels of uE3. Estriol is produced by the placenta partly in response to dehydroepiandrosterone sulfate production in the fetal adrenal gland (28). Given that dehydroepiandrosterone sulfate levels are closely tied to immune system function-wherein higher levels are known to heighten function in times of stress (29-31) - it is possible that low uE3 levels may suggest low dehydroepiandrosterone sulfate levels and as such, minimal immune system triggering by dehydroepiandrosterone sulfate.

It is possible that among this subset a stressor early in pregnancy (e.g., oxidative stress as a result of maternal hypertension or another factor) could have triggered stress-induced immunosuppression (32). Such triggering may have taken place despite an already active inflammatory response in the mother or fetus, or perhaps this triggering was related to a single risk or multiple risks that provoked inflammation and were also stress-inducing. Models of risks that cause oxidative stress and are associated with an elevated autoimmune response and an increased inflammatory response are well developed in research focused on the pathophysiological effects of smoking and hypertension $(33,34)$.

We found that preterm $/ \mathrm{BPD}^{+}$pregnancies that had a high AFP, high hCG, and/or low uE3 level were substantially more likely to be diagnosed as being hypertensive than other pregnancies within the $\mathrm{BPD}^{+}$group that did not have a biomarker risk present $(48.8 \%$ vs. $17.1 \%, P<0.01)$. This finding supports the idea that preterm pregnancies with BPD, which have one or more biomarker risk present in the second trimester, may constitute a subset where there was earlier pregnancy stress that might have led to adaptations reflected by biomarker levels. The fact that results persisted but were reduced when pregnancies with hypertension were excluded from biomarker-BPD analyses suggests other genetic and/or environment factors are also likely contributors to early stress and stress-related adaptations in this group. Candidates might include maternal conditions like chorioamnionitis and asthma, which are associated with oxidative stress and with BPD (35-37), and maternal heart disease, which is also associated with oxidative stress during pregnancy and with genetic factors that may predispose a woman to heart disease and other conditions like asthma (38).

The greater likelihood of early intrauterine stressors having led to intrauterine adaptations in the $\mathrm{BPD}^{+}$biomarker risk group vs. the $\mathrm{BPD}^{+}$no biomarker risk group may be further demonstrated by the greater number of SGA births in the biomarker group $(26.8 \%$ vs. $4.3 \%, P<0.05)$, and the tendency toward asymmetric undergrowth/brain-sparing in the biomarker risk group as compared with the no biomarker risk group (as indicated by significantly lower weights in the biomarker group but not significantly smaller head sizes and greater mean head circumference/birth weight ratios). 
Further indication of intrauterine adaptation to stress in the $\mathrm{BPD}^{+}$biomarker risk group may be demonstrated by the lessened frequency of intraventricular hemorrhage in this group as compared with the $\mathrm{BPD}^{+}$no biomarker risk group $(20.7 \%$ vs. $44.5 \%, P<0.01)$. Such a pattern may be directly related to greater early oxidative stress in the biomarker risk group as a result of maternal hypertension and other yet unknown factors related to early fetal growth restriction and hypoxia that might accelerate adaptive mechanisms that protect against some brain injuries (39-41).

This study has significant strengths, including use of a large population-based sample of screened pregnancies for which a great deal was known about risks associated with preterm birth, BPD, and the biomarkers of study. Still, some limitations should be considered. For instance, some data obtained from vital records used in study exclusions may have been subject to underreporting, including information about maternal characteristics. We have no reason to believe underreporting would have been biased toward any analyte grouping and as such, we believe any error would have underestimated RRs.

Although the study subset is highly similar to the overall California 2005-2008 birth cohort $(n=2,228,561)$ in terms of maternal characteristics such as race, age, and nulliparity (e.g., $56.4 \%$ Hispanic vs. $52.1 \%$ for our study vs. population, $28.3 \%$ vs. $28.8 \%$ white, $4.8 \%$ vs. $5.3 \%$ black, $17.8 \%$ vs. $16.9 \%$ maternal age over 34 years, $40.2 \%$ vs. $39.5 \%$ nulliparity), it should be noted that there are some key differences between California and other populations. For example, although the proportion of Hispanic births in California is quite high (e.g., $>50 \%$ of all births), in the United States as a whole this proportion is $<20 \%$ (ref. 42). Such patterns point to the importance of comparable studies being carried out on other samples and populations to aid in understanding the generalizability of our findings.

It should also be noted that the rate of preterm birth $<30 \mathrm{wk}$ in this study was substantially lower than in the overall population $(0.3 \%$ vs. $1.1 \%)$. Although this reflects our intention to focus on a group of pregnancies without chromosomal or structural defects for which there was no history of smoking, diabetes, or amniotic fluid abnormalities, it also points to the need for future study that includes a broader range of preterm births. Although we believe these exclusions were necessary given known associations between these factors and the biomarkers of study $(43,44,45)$, it is possible that future studies might examine these patterns using other prenatal serum biomarkers that might be related to inflammation and/or immunosuppression but may not be as closely related to smoking, diabetes, and/ or amniotic fluid abnormalities. Similarly, although we believe our choice to focus on a subset of BPD infants with a clearly defined phenotype allowed for greater control of confounders in terms of analysis of biomarker-BPD relationships, this pursuit also means that follow-up studies may benefit from examining prenatal biomarker-BPD relationships using a more broadly defined phenotype. Such analyses would also benefit from expansion beyond the biomarkers studied in our analyses due to their relationship with characteristics that may be present in a broader BPD grouping (e.g., birth defects; ref. 45).

\section{METHODS}

The study population was drawn from a set of 1,476,249 singleton pregnancies participating in the California Expanded AFP Screening Program administered by the Genetic Disease Screening Program within the California Department of Public Health with expected dates of confinement in 2005-2008.

All included pregnancies had gestational dating that was based on ultrasound measurements and had screening results that were successfully linked to birth certificates that indicated a live birth between 20 and 44 completed wk of gestation. All women had a maternal age between 12 and 60 years and a known self-identified race/ethnicity. From this set, we excluded all pregnancies where the Genetic Disease Screening Program records (prenatal screening records, newborn screening records, chromosomal, and neural tube defect registries), the linked vital statistics birth records, and/ or the linked neonatal intensive care unit records indicated that the mother had a history of smoking, was diabetic before or during pregnancy, and/or had abnormal amniotic fluid levels (diagnosed poly- or oligiohydramnios) given that such patterns are known to be associated with unusually high or low serum levels of target biomarkers $(43,44)$. We also excluded any pregnancy where one or more data source indicated that the infant had a diagnosed chromosomal or structural defect given similar concerns. A total of 662,889 pregnancies met inclusionary and exclusionary criteria for the study.

All of the second-trimester biomarker results were obtained as part of routine second-trimester prenatal screening and had blood samples collected between 15 and $20 \mathrm{wk}$ of completed gestation. Samples were sent to one of seven regional laboratories in California for serum testing of AFP, hCG, and uE3. All laboratories are part of a network that adheres to the same protocols for measuring biomarkers in secondtrimester maternal serum using fully automated equipment (Auto DELFIA; Perkin Elmer Life Sciences, Waltham, MA). At these laboratories, results were entered directly into the state database along with patient information, which was then used to translate the biomarker value into an MoM used for final result interpretation. All women in the sample had AFP, hCG, and uE3 MoMs that were adjusted for gestational age, maternal weight (as a proxy for blood volume), and race/ethnicity.

Neonatal intensive care unit data were obtained from the California Perinatal Quality Care Collaborative database, which stores clinical data on $>90 \%$ of all neonates who receive neonatal intensive care in California (46). The California Perinatal Quality Care Collaborative includes neonatal intensive care unit data from 128 hospitals statewide, which are entered prospectively into the California Perinatal Quality Care Collaborative data collection system via a confidential Internet site that is accessible at these partner hospitals. The data set does not contain personal identifiers such as hospital ID number, name, address, or social security number. Data are subjected to range and logic tests and missing data items are confirmed. For this study, the $\mathrm{BPD}^{+}$and $\mathrm{BPD}^{-}$groups were selected solely based on California Perinatal Quality Care Collaborative data.

To study a group of infants with a more clearly defined and consistent clinical phenotype, in addition to meeting the commonly accepted threshold for BPD diagnosis of supplemental oxygen at $36 \mathrm{wk}$ postmenstrual age $(47,48), \mathrm{BPD}^{+}$infants included as cases in this study were in the hospital and were on continuous supplemental oxygen at $36 \mathrm{wk}$ postmenstrual age, had received positive pressure ventilation for a minimum of $3 \mathrm{~d}$, had a gestational age between $25 \mathrm{wk}$ and zero $\mathrm{d}$ and $29 \mathrm{wk}$ and six $\mathrm{d}$ inclusive, had a birth weight $<1,500 \mathrm{~g}$, and had no major birth defects, no chromosomal abnormalities, and no surgeries except for circumcision or patent ductus arteriosus ligation. We did not exclude infants with necrotizing enterocolitis unless it necessitated abdominal surgical intervention. The $\mathrm{BPD}^{-}$group included all remaining preterm births with gestational ages at birth that were $<30$ completed wk who were not reported as being on oxygen at $28 \mathrm{~d}$ after birth or at $36 \mathrm{wk}$ postmenstrual age.

Analyses utilized logistic binomial regression methods to estimate relative risks (RRs). To measure whether target maternal characteristics were associated with an elevated risk of preterm 
birth occurring before 30-wk gestation without BPD (preterm/ $\mathrm{BPD}^{-}$) or for preterm birth occurring before $30 \mathrm{wk}$ with BPD (preterm $/ \mathrm{BPD}^{+}$), the rate of preterm $/ \mathrm{BPD}^{-}$and preterm $/ \mathrm{BPD}^{+}$births was calculated for the following pregnancy groupings: non-white race/ethnicity (by subgroup) as compared to white race/ethnicity, maternal age $<18$ years or $>34$ years as compared with maternal age $18-34$ years, maternal weight $<5$ th or $>95$ th weight percentile as compared with weight between the 5 th and 95th percentile (based on race/ethnicity weight for gestational age at initial prenatal testing norms for the entire screened population), and parity $=1$ or unknown as compared to pregnancies with parity $\geq 2$. The relationship between biomarkers and preterm $/ \mathrm{BPD}^{-}$and preterm $/ \mathrm{BPD}^{+}$ was measured by comparing the rate of each independent outcome within each of the abnormal biomarker groupings (AFP, hCG, and/ or $\mathrm{uE} 3 \mathrm{MoM} \leq 5$ th or $\geq 95$ th percentile) to the rate in the "no abnormal biomarkers" grouping (AFP, hCG, and uE3 between the 5 th and 95th percentiles). Biomarker models included all maternal characteristics found to be predictive of preterm $/ \mathrm{BPD}^{-}$or preterm/BPD ${ }^{+}$ in initial logistic analyses. SGA birth was also included in these models. Infants were considered SGA if they had a birth weight for gestational age that was below the 10th percentile based on published smoothed birth weight for gestational age norms (smoothed across gender and race/ethnicity groupings; ref. 49).

In addition to estimates of RRs using logistic binomial regression, differences in maternal and infant characteristics based on the presence or absence of any biomarker risk were examined within the $\mathrm{BPD}^{+}$ grouping using $\chi^{2}$-tests and $t$-tests.

All analyses were done using Statistical Analysis Software, version 9.1 (Cary, NC). Methods and protocols for the study were approved by the Committee for the Protection of Human Subjects within the Health and Human Services Agency of the State of California and the institutional review board of Stanford University.

\section{STATEMENT OF FINANCIAL SUPPORT}

Partial funding support for this project was obtained from the National Institutes of Health/National Heart, Lung, and Blood Institute (RC2 HL101748) and from the March of Dimes Prematurity Center at Stanford University School of Medicine.

\section{REFERENCES}

1. Northway WH Jr, Rosan RC, Porter DY. Pulmonary disease following respirator therapy of hyaline-membrane disease. Bronchopulmonary dysplasia. N Engl J Med 1967;276:357-68.

2. Husain AN, Siddiqui NH, Stocker JT. Pathology of arrested acinar development in postsurfactant bronchopulmonary dysplasia. Hum Pathol 1998;29:710-7.

3. Deakins KM. Bronchopulmonary dysplasia. Respir Care 2009;54:1252-62.

4. Baraldi E, Filippone M. Chronic lung disease after premature birth. N Engl J Med 2007;357:1946-55.

5. Kramer BW, Kallapur S, Newnham J, Jobe AH. Prenatal inflammation and lung development. Semin Fetal Neonatal Med 2009;14:2-7.

6. Bose C, Laughon M, Allred EN, et al.; Elgan Study Investigators. Blood protein concentrations in the first two postnatal weeks that predict bronchopulmonary dysplasia among infants born before the $28^{\text {th }}$ week of gestation. Pediatr Res 2011;69:347-53.

7. Baier RJ, Majid A, Parupia H, Loggins J, Kruger TE. CC chemokine concentrations increase in respiratory distress syndrome and correlate with development of bronchopulmonary dysplasia. Pediatr Pulmonol 2004;37:137-48.

8. Jónsson B, Tullus K, Brauner A, Lu Y, Noack G. Early increase of TNF $\alpha$ and IL- 6 in tracheobronchial aspirate fluid indicator of subsequent chronic lung disease in preterm infants. Arch Dis Child Fetal Neonatal Ed 1997;77:F198-201.

9. Ramsay PL, DeMayo FJ, Hegemier SE, Wearden ME, Smith CV, Welty SE. Clara cell secretory protein oxidation and expression in premature infants who develop bronchopulmonary dysplasia. Am J Respir Crit Care Med 2001;164:155-61.

10. Beresford MW, Shaw NJ. Detectable IL-8 and IL-10 in bronchoalveolar lavage fluid from preterm infants ventilated for respiratory distress syndrome. Pediatr Res 2002;52:973-8.
11. Yoon BH, Romero R, Jun JK, et al. Amniotic fluid cytokines (interleukin-6, tumor necrosis factor- $\alpha$, interleukin- $1 \beta$, and interleukin-8) and the risk for the development of bronchopulmonary dysplasia. Am J Obstet Gynecol 1997;177:825-30.

12. Kim BI, Lee HE, Choi CW, et al. Increase in cord blood soluble E-selectin and tracheal aspirate neutrophils at birth and the development of new bronchopulmonary dysplasia. J Perinat Med 2004;32:282-7.

13. Ambalavanan N, Carlo WA, D’Angio CT, et al.; Eunice Kennedy Shriver National Institute of Child Health and Human Development Neonatal Research Network. Cytokines associated with bronchopulmonary dysplasia or death in extremely low birth weight infants. Pediatrics 2009;123:1132-41.

14. Velten M, Heyob KM, Rogers LK, Welty SE. Deficits in lung alveolarization and function after systemic maternal inflammation and neonatal hyperoxia exposure. J Appl Physiol 2010;108:1347-56.

15. Yamashita T, Nakane A, Watanabe T, Miyoshi I, Kasai N. Evidence that a-fetoprotein suppresses the immunological function in transgenic mice. Biochem Biophys Res Commun 1994;201:1154-59.

16. Filella X, Molina R, Alcover J, Coca F, Zarco MA, Ballesta AM. Influence of AFP, CEA and PSA on the in vitro production of cytokines. Tumour Biol 2001;22:67-71.

17. Potapovich AI, Pastore S, Kostyuk VA, et al. $\alpha$-Fetoprotein as a modulator of the pro-inflammatory response of human keratinocytes. Br J Pharmacol 2009;158:1236-47.

18. van der Zee M, Dik WA, Kap YS, et al. Synthetic human chorionic gonadotropin-related oligopeptides impair early innate immune responses to Listeria monocytogenes in mice. J Infect Dis 2010;201:1072-80.

19. Marshall I, Ugrasbul F, Manginello F, et al. Congenital hypopituitarism as a cause of undetectable estriol levels in the maternal triple-marker screen. J Clin Endocrinol Metab 2003;88:4144-8.

20. Harel S, Tomer A, Barak Y, Binderman I, Yavin E. The cephalization index: a screening device for brain maturity and vulnerability in normal and intrauterine growth retarded newborns. Brain Dev 1985;7:580-4.

21. Jelliffe-Pawlowski LL, Baer RJ, Currier RJ. Second trimester serum predictors of preterm birth in a population-based sample of low-risk pregnancies. Prenat Diagn 2010;30:727-33.

22. Yaron Y, Cherry M, Kramer RL, et al. Second-trimester maternal serum marker screening: maternal serum alpha-fetoprotein, beta-human chorionic gonadotropin, estriol, and their various combinations as predictors of pregnancy outcome. Am J Obstet Gynecol 1999;181:968-74.

23. Dugoff L, Hobbins JC, Malone FD, et al; FASTER Trial Research Consortium. Quad screen as a predictor of adverse pregnancy outcome. Obstet Gynecol 2005;106:260-7.

24. Cole LA. Biological functions of hCG and hCG-related molecules. Reprod Biol Endocrinol 2010;8:102.

25. Mizejewski GJ. Biological roles of $\alpha$-fetoprotein during pregnancy and perinatal development. Exp Biol Med (Maywood) 2004;229:439-63.

26. Mizejewski GJ. Physiology of $\alpha$-fetoprotein as a biomarker for perinatal distress: relevance to adverse pregnancy outcome. Exp Biol Med (Maywood) 2007;232:993-1004.

27. Handschuh K, Guibourdenche J, Tsatsaris V, et al. Human chorionic gonadotropin produced by the invasive trophoblast but not the villous trophoblast promotes cell invasion and is down-regulated by peroxisome proliferator-activated receptor- $\gamma$. Endocrinology 2007; 148:5011-9.

28. Zbella EA, Ilekis J, Scommegna A, Benveniste R. Competitive studies with dehydroepiandrosteronesulfateand $16 a$-hydroxydehydroepiandrosterone sulfate in cultured human choriocarcinoma JEG-3 cells: effect on estrone, $17 \beta$-estradiol, and estriol secretion. J Clin Endocrinol Metab 1986;63:751-7.

29. Khorram O, Vu L, Yen SS. Activation of immune function by dehydroepiandrosterone (DHEA) in age-advanced men. J Gerontol A Biol Sci Med Sci 1997;52:M1-7.

30. Mitchell JB, Dugas JP, McFarlin BK, Nelson MJ. Effect of exercise, heat stress, and hydration on immune cell number and function. Med Sci Sports Exerc 2002;34:1941-50.

31. Buhimschi CS, Turan OM, Funai EF, et al. Fetal adrenal gland volume and cortisol/dehydroepiandrosterone sulfate ratio in inflammation-associated preterm birth. Obstet Gynecol 2008;111:715-22. 
32. Råberg L, Grahn $\mathrm{M}$, Hasselquist $\mathrm{D}$, Svensson $\mathrm{E}$. On the adaptive significance of stress-induced immunosuppression. Proc Biol Sci 1998;265:1637-41.

33. van der Vaart H, Postma DS, Timens W, ten Hacken NH. Acute effects of cigarette smoke on inflammation and oxidative stress: a review. Thorax 2004;59:713-21.

34. Verlohren S, Muller DN, Luft FC, Dechend R. Immunology in hypertension, preeclampsia, and target-organ damage. Hypertension 2009;54:439-43.

35. Cheah FC, Jobe AH, Moss TJ, Newnham JP, Kallapur SG. Oxidative stress in fetal lambs exposed to intra-amniotic endotoxin in a chorioamnionitis model. Pediatr Res 2008;63:274-9.

36. De Luca G, Olivieri F, Melotti G, Aiello G, Lubrano L, Boner AL. Fetal and early postnatal life roots of asthma. J Matern Fetal Neonatal Med 2010;23:Suppl 3:80-3.

37. Miller JD, Benjamin JT, Kelly DR, Frank DB, Prince LS. Chorioamnionitis stimulates angiogenesis in saccular stage fetal lungs via CC chemokines. Am J Physiol Lung Cell Mol Physiol 2010;298:L637-45.

38. Leineweber K, Heusch G. $\beta 1$ - and $\beta 2$-Adrenoceptor polymorphisms and cardiovascular diseases. Br J Pharmacol 2009;158:61-9.

39. Hadi HA. Fetal cerebral maturation in hypertensive disorders of pregnancy. Obstet Gynecol 1984;63:214-9.

40. Miller BA, Perez RS, Shah AR, Gonzales ER, Park TS, Gidday JM. Cerebral protection by hypoxic preconditioning in a murine model of focal ischemia-reperfusion. Neuroreport 2001;12:1663-9.
41. Ancel PY, Marret S, Larroque B, et al.; Epipage Study Group. Are maternal hypertension and small-for-gestational age risk factors for severe intraventricular hemorrhage and cystic periventricular leukomalacia? Results of the EPIPAGE cohort study. Am J Obstet Gynecol 2005;193:178-84.

42. Martin JA, Hamilton BE, Sutton PD, et al. Births: final data for 2007. Natl Vital Stat Rep 2010;58:1-85.

43. Huttly W, Rudnicka A, Wald NJ. Second-trimester prenatal screening markers for Down syndrome in women with insulin-dependent diabetes mellitus. Prenat Diagn 2004;24:804-7.

44. Gagnon A, Wilson RD, Audibert F, et al.; Society of Obstetricians and Gynaecologists of Canada Genetics Committee. Obstetrical complications associated with abnormal maternal serum markers analytes. J Obstet Gynaecol Can 2008;30:918-49.

45. Wald NJ, Kennard A, Hackshaw A, McGuire A. Antenatal screening for Down's syndrome. J Med Screen 1997;4:181-246.

46. Gould JB. The role of regional collaboratives: the California Perinatal Quality Care Collaborative model. Clin Perinatol 2010;37:71-86.

47. Jobe AH, Bancalari E. Bronchopulmonary dysplasia. Am J Respir Crit Care Med 2001;163:1723-29.

48. Walsh MC, Szefler S, Davis J, et al. Summary proceedings from the bronchopulmonary dysplasia group. Pediatrics 2006;117:S52-6.

49. Alexander GR, Himes JH, Kaufman RB, Mor J, Kogan M. A United States national reference for fetal growth. Obstet Gynecol 1996;87:163-8. 